Marquette University

e-Publications@Marquette

College of Nursing Faculty Research and

Publications

Nursing, College of

$2-1-2016$

The Mediating Effects of Positive Cognitions on Autism Caregivers' Depression and Their Children's Challenging Behaviors

Abir K. Bekhet

Marquette University, abir.bekhet@marquette.edu

Accepted version. Archives of Psychiatric Nursing, Vol. 30, No. 1 (February 2016): 13-18. DOI. (C) 2016 Elsevier (WB Saunders). Used with permission. 


\title{
The Mediating Effects of Positive Cognitions on Autism Caregivers' Depression and Their Children's Challenging Behaviors
}

\author{
Abir K. Bekhet \\ College of Nursing, Marquette University \\ Milwaukee, WI
}

\begin{abstract}
Caregivers of persons with Autism Spectrum Disorders (ASD) are prone to depression and psychological problems, which have an impact on their children's challenging behaviors. Positive cognitions include specific positive thinking patterns that enhance one's ability to effectively manage daily activities and promote mental health. The purpose of this research is to test the mediating effects of positive cognitions on the relationship between caregivers' depression and their children's challenging behaviors among 117 caregivers of persons with ASD. Positive cognitions were found to have mediating effects on the relationship between caregiver's depression and their children's challenging behaviors in this sample of caregivers of persons with ASD. Nurses are in a strategic position to include in their interventions those strategies that strengthen positive cognitions in order to improve the caregivers' positive cognitions and well-being, which, in turn will have an impact on their children's challenging behaviors.

The rate of autism spectrum disorders (ASD) has steadily increased over the last decades. Currently, one in sixty-eight children are affected by ASD; a bio-neurological developmental disability that affects a person's ability to communicate and to interact socially (Baker and Jeste, 2015 and National Autism Association, 2014).
\end{abstract}


Persons with ASD can be aggressive, impulsive, self-injurious, and hyperactive. In addition, they might have short attention span, temper tantrums, and unusual eating and sleeping habits (Hoffman et al., $\underline{2008}$ and National Autism Association, 2014). ASD is a lifelong disorder; its symptoms appear before age three and to date, there is no cure for ASD (American Psychiatric Association (APA), 2000; National Autism Association, 2014). There are numerous co-morbid conditions associated with ASD including but not limited to; asthma, epilepsy, digestive disorders, anxiety disorder, bipolar disorder, attention deficit hyperactivity disorders, obsessive-compulsive disorders, sleeping disorders, and immune disorders (National Autism Association, 2014). Therefore, caregiving for these children is demanding, and can place a heavy toll on family caregivers' physical and psychological well-being (Bekhet, 2014, Benson, 2006, Kirby et al., 2015 and Phetrasuwan and Miles, 2009).

Research has shown that caregivers of persons with ASD report depressive symptoms (Ekas et al., 2010 and Firth and Dryer, 2013) and previous studies showed that parents of persons with ASD are at higher risk for developing depression than parents of normally developed children (Benson, 2006 and Khanna et al., 2011). On the other hand, research has shown that persons with ASD themselves may experience anxiety and depression (Almansour et al., 2013 and Strang et al., 2012), which can in turn elevate caregivers' depression. It has been documented that more than one-third of mothers of toddlers and adolescents with ASD had higher scores on a depression scale than the clinical cut-off scores (Smith, Seltzer, TagerFlusberg, Greenberg, \& Carter, 2008).

There is ample research that has focused on the relationship between maternal depression and childhood behavioral problems (Baker et al., 2011, Karazsia and Wildman, 2009 and Karst and Van Hecke, 2012). A recent study conducted by Raposa, Hammen, Brennan, and Najman (2014), found that prenatal maternal depressive symptoms predicted worse physical health during early childhood for offspring, and this effect was partially explained by ongoing maternal depression in early childhood. Furthermore, their research showed that maternal depression had a significant total indirect effect on youth depression via early childhood health and its psychosocial consequences. In addition, research has shown that the challenging permission has been granted for this version to appear in e-Publications@Marquette. Elsevier (WB Saunders) does not grant permission for this article to be further copied/distributed or hosted elsewhere without the express permission from Elsevier (WB Saunders). 
behaviors of children with ASD can lead to poor maternal psychological well-being (Allik et al., 2006, Herring et al., 2006 and Karst and Van Hecke, 2012) and impaired maternal health related quality of life (Allik et al., 2006). However, previous studies have not examined the mediating effects of positive cognitions on the relationship between caregivers' depression and their children's challenging behaviors as proposed in this study. The study will provide direction for the development of a positive thinking training intervention to help caregivers of persons with ASD to combat their depression and anxiety that will in turn improve their children's challenging behaviors.

\section{Theoretical framework}

The study is informed by Goodman and Gotlib (1999), integrative model for understanding children's risk in relation to maternal depression. According to Goodman and Gotlib's theory, one of the identified risks of child's psychopathology is the child's exposure to negative maternal cognitions, behaviors, and affect. The study is also informed by Karazsia and Wildman (2009)conceptual model of maternal affect, and children's behavior ( Karazsia \& Wildman, 2009). According to Karazsia and Wildman's model, maternal affect has a direct influence on the child's behavior problems. Furthermore, the model hypothesized that parenting strategies mediate pathways between maternal affect and child's behavior problems. Accordingly, using Goodman and Gotlib's model as well as Karazsia and Wildman's model; we hypothesize that positive cognitions will mediate pathways between caregivers' depression and the children's challenging behaviors among caregivers of persons with ASD.

Positive cognitions are defined as "specific positive thinking patterns that enhance one's ability to effectively manage daily activities and promote mental health" (Bekhet and Zauszniewski, 2008 and Zauszniewski et al., 2002). Empirical evidence suggests that positive cognitions are associated with minimizing the severity of depressive symptoms in women with type 2 diabetes (Zauszniewski et al., 2002). Also positive cognitions have been shown to help elders to reframe stressful life events, such as relocation, more positively (Bekhet, Zauszniewski, \& Wykle, 2008). However, previous research did not investigate whether positive cognitions mediate the

Archives of Psychiatric Nursing, Vol. 30, No. 1 (February 2016): pg. 13-18. DOI. This article is @ Elsevier (WB Saunders) and permission has been granted for this version to appear in e-Publications@Marquette. Elsevier (WB Saunders) does not grant permission for this article to be further copied/distributed or hosted elsewhere without the express permission from Elsevier (WB Saunders). 
relationship between caregivers' depression and their children's challenging behaviors (problem behavior domains and social behavior domains) as proposed in this study. This study will address the following research questions:

Q1. What are the effects of positive cognitions on:

a. Children social behavior? [Fig. 1, Q1(a)]

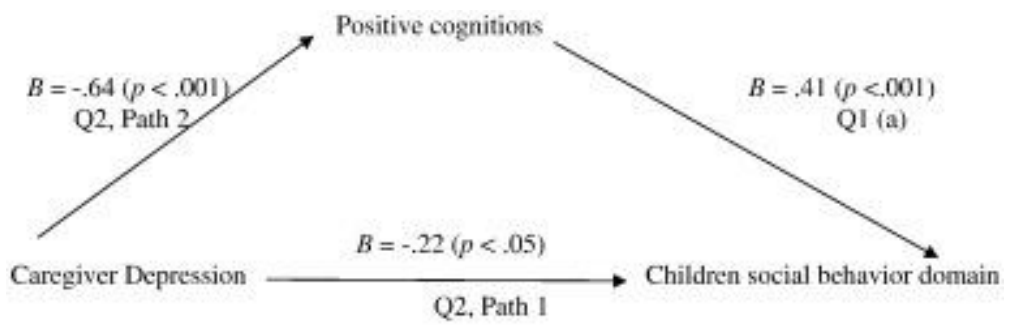

Note: Values reported are betas.

* $\mathrm{p}<.05 * \mathrm{p} p<.01 * * * \mathrm{p}<.001$

Fig. 1. Mediation of positive cognition between caregivers' depression and children's social behavior domains.

Note: Values reported are betas.

$* P<.05 * * P<.01 * * * P<.001$.

b. Children problem behavior? [Fig. 2, Q1 (b)]

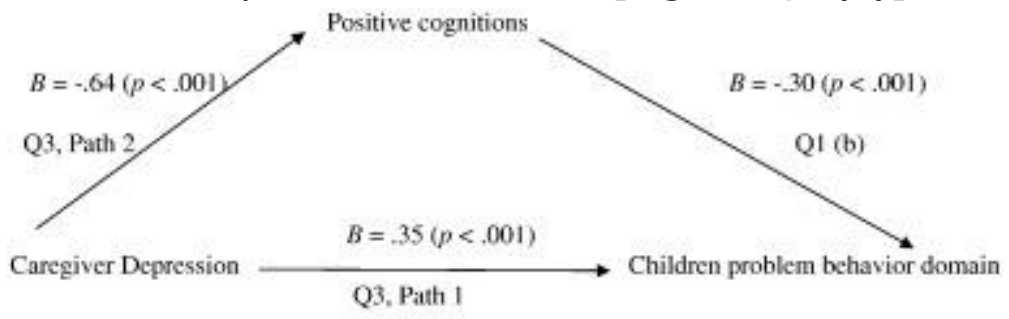

Note: Values reported are betas.

" $\mathrm{p}<.05 * 0 \mathrm{p}<.01$ *t*0 $\mathrm{p}<.001$

Fig. 2. Mediation of positive cognition between caregivers' depression and children's problem behavior domains.

Note: Values reported are betas.

$* P<.05 * * P<.01 * * * P<.001$.

Q2.Do positive cognitions mediate the relationship between caregivers' depression and their children's social behaviors? (Fig. 1, Q2)

Q3. Do positive cognitions mediate the relationship between caregivers' depression and their children's problem behaviors?

(Fig. 2, Q3)

Archives of Psychiatric Nursing, Vol. 30, No. 1 (February 2016): pg. 13-18. DOI. This article is @ Elsevier (WB Saunders) and permission has been granted for this version to appear in e-Publications@Marquette. Elsevier (WB Saunders) does not grant permission for this article to be further copied/distributed or hosted elsewhere without the express permission from Elsevier (WB Saunders). 
NOT THE PUBLISHED VERSION; this is the author's final, peer-reviewed manuscript. The published version may be accessed by following the link in the citation at the bottom of the page.

\section{Method}

A convenience sample of 117 caregivers of persons with ASD, both men and women, of all ages and living arrangements comprises the study sample. Inclusion criteria for this study consist of the ability to read and understand English, being the caregiver of one or more persons with a diagnosis of ASD, and having Internet access and residence in the United States. No subjects were excluded on the basis of gender, race, or socio-economic status. Participants were recruited by convenience sampling from The Interactive ASD Network (IAN) Research registry service provided by the Kennedy Krieger Institute and Johns Hopkins Medicine-Baltimore, sponsored by ASD Speaks Foundation. The registry has over 34,000 participants, including caregivers of children with ASD. The institutional review board (IRB) approval was obtained from the university. Caregivers of persons with ASD who were willing to be contacted by e-mail received an IRB approved flyer by IAN. An IAN request directed potential participants to the Internet website (www.surveymonkey.com) where a consent form and a link to the study questionnaires were housed. Informed consent was obtained before participants were able to access the questionnaires. Potential participants were offered an incentive for participation in the study, and those who chose to accept the incentive provided their e-mail address at the end of the survey. The research team then sent the participant a code that could be redeemed for $\$ 10$ at www.amazon.com. e-Mail addresses were destroyed after incentive codes were sent to participants. Data were collected and analyzed during the months of June and July of 2014.

\section{Measures}

Positive Cognitions. The Depressive Cognition Scale (DCS; Zauszniewski, 1995) was used to measure positive cognitions. The DCS measures depressive cognitions when its scoring is reversed because all the scale items are phrased in a positive direction (Zauszniewski, Chung, Krafcik, \& Sousa, 2001). The scale is based on Erikson's psychosocial stages of development, and each of the eight depressive cognition items on the scale reflects unsuccessful resolution of one of the stages outlined by Erikson (Zauszniewski, 1995); the DCS measures depressive cognitions when scoring is reversed. In this permission has been granted for this version to appear in e-Publications@Marquette. Elsevier (WB Saunders) does not grant permission for this article to be further copied/distributed or hosted elsewhere without the express permission from Elsevier (WB Saunders). 
study, the scores were not reversed in order to measure positive cognitions. The DCS consists of 8 items scored on a 6-point Likert type scale from strongly agree (5) to strongly disagree (0), to indicate the degree to which a particular statement describes respondents' current thoughts ( Zauszniewski, 1995 and Zauszniewski et al., 2001). Scores may range from 0 to 40 . A higher composite score demonstrates a greater number of positive cognitions (Zauszniewski, 1997). Zauszniewski (1995) has reported acceptable internal consistency $(a=.78)$, and construct validity as indicated by significant correlations with measures of depression $(r=-.54, P<.001)$, resourcefulness (.37, $P<.001)$, and adaptive functioning $(r=.60, P<.001)$. Confirmatory factor analysis indicated the presence of a single factor with all item factor loadings exceeding .30; $40 \%$ of the total variance of the scale was explained ( Zauszniewski, 1997 and Zauszniewski et al., 2001). Examples of the DCS scale items are: "I am a worthwhile human being," "I believe that life is worth living," and "I am hopeful about my future." Cronbach's a in this study was .85.

Depression was measured by the Center for Epidemiologic Studies Depression Scale (CES-D; Radloff, 1977). The CES-D is a 20item Likert-type scale ranging from 0 "rarely or none of the time" to 3 "most or all of the time"; it was initially designed to evaluate depressive symptoms in adults. However, research has shown that the CES-D is reliable and valid in general and clinical populations as well (Radloff, 1977). Subjects are asked to indicate how frequently they have experienced depressive feelings and behaviors during the past week. Scores may range from 0 to 60 with higher scores indicating the presence of more depressive symptoms. The CES-D is reliable as evidenced by a Cronbach's alpha of .92 in mothers of persons with ASD (Ekas, Whitman, \& Shivers, 2009). Factor analysis resulted in four factors accounting for $48 \%$ of the variance. CES-D correlated significantly with the Hamilton Rating Scale and the Raskin Rating Scale, suggesting construct validity (Radloff, 1977). Cronbach's a in this study was .91. A cutoff scores of 16 or greater indicating a risk for clinical depression (Lewinsohn, Seeley, Roberts, \& Allen, 1997). The mean scores of caregivers of persons with ASD in this study is 16.34 $(\mathrm{SD}=11.81)$.

Children's challenging behaviors (Social behavior and problem behavior) was measured by the Nisonger Child Behavior Rating Form

Archives of Psychiatric Nursing, Vol. 30, No. 1 (February 2016): pg. 13-18. DOI. This article is (C Elsevier (WB Saunders) and permission has been granted for this version to appear in e-Publications@Marquette. Elsevier (WB Saunders) does not grant permission for this article to be further copied/distributed or hosted elsewhere without the express permission from Elsevier (WB Saunders). 
(Nisonger CBRF) and was used to identify the problem behaviors as well as the social adaptive behaviors in children with ASD (Aman et al., 1996 and Tassé et al., 1996). The study used "the parent version" and it was completed by the caregivers. There are 76 items in 2 domains: social (10 items) and problem (66 items) behaviors. Social behavior domains include: compliant/calm (6 items) and adaptive/social (4 items), scored on a 0-3 Likert scale (not true to always true). Problem behavior domains include: (1) Disruptive Behavior Disorder subscales: conduct problems (16 items), insecure/anxious (15 items), and (2) ADHD subscales: hyperactive ( 9 items), self-injury/stereotypic ( 7 items), self-isolated/ritualistic ( 8 items) and overly sensitive (5 items), scored on a 0-3 Likert scale from 0 , did not occur or not a problem, to 3 , occurred a lot or was a severe problem. The Problem Behavior domain has adequate inter-rater reliability and convergent validity was established between the Nisonger CBRF and the ABC ( Aman et al., 1996 and Tassé et al., 1996). Convergent and discriminant validity was found between the BPI-01 and the NCBRF. In a sample of 330 children and adolescents with ASDs alpha coefficient, a measure of internal consistency, was .79 for Compliant/Calm and .63 for Adaptive Social. Coefficients for Problem Behaviors were as follows: Conduct Problem, .92; Insecure/Anxious, .87; Hyperactive, .89; SelfInjury/Stereotypic, .73; Self-Isolated/Ritualistic, .72; and Overly Sensitive $=.71$ (Lecavalier, Leone, \& Wiltz, 2006). Cronbach's alphas for the Social Behavior domain and the Problem Behavior domain subscales in this study were .87 and .94 , respectively.

\section{Data management/analysis}

Descriptive statistics were used to describe the sample characteristics. Preliminary data analyses were conducted to ensure that the statistical assumptions for multiple regression were not violated. Simple linear regression was used to examine the effects of positive cognitions on children social behavior domains and the children problem behavior domains.

In addition, Hierarchical regression was used to examine:

1) The mediating effects of positive cognitions on the relationship between caregivers' depression and children's social behavior domains (Fig. 1, Q2, Table 1).

Archives of Psychiatric Nursing, Vol. 30, No. 1 (February 2016): pg. 13-18. DOI. This article is (C Elsevier (WB Saunders) and permission has been granted for this version to appear in e-Publications@Marquette. Elsevier (WB Saunders) does not grant permission for this article to be further copied/distributed or hosted elsewhere without the express permission from Elsevier (WB Saunders). 
NOT THE PUBLISHED VERSION; this is the author's final, peer-reviewed manuscript. The published version may be accessed by following the link in the citation at the bottom of the page.

Table 1. Tests of Mediation of the Effect of Positive Cognitions on the Relationship Between caregiver's Depression and Their children's Challenging Behavior (Social Behavior and Problem Behavior).

Test (1) for first mediation ${ }^{1}$ Test ( 2 ) for second mediation ${ }^{2}$

\begin{tabular}{clllll}
\multicolumn{1}{c}{ Variable } & \multicolumn{2}{c}{ Step 1 B } & \multicolumn{2}{c}{ Step 2 B } & \multicolumn{2}{c}{ Step 1 B } & \multicolumn{1}{c}{ Step 2 B } \\
\cline { 2 - 4 } Caregivers' depression & $-.22 *$ & .07 & $.35 * * *$ & $.26 *$ \\
F value & $5.89 *$ & $11.96 * * *$ & $16.00 * * *$ & $8.73 * * *$
\end{tabular}

$* P<.05 * * P<.01 * * * P<.001$.

1 Tests of mediation of the effect of positive cognitions on the relationship between caregiver's depression and their children's social behavior.

2 Tests of mediation of the effect of positive cognitions on the relationship between caregiver's depression and their children's problem behavior.

2) The mediating effects of positive cognitions on the relationship between caregivers' depression and children's problem behavior domains (Fig. 2, Q3, Table 1):

More specifically, a two-step hierarchical regression was used to test the mediating effects of positive cognitions on the relationship between caregiver of persons with ASD depression and their children's social behaviors. In this regression, three conditions were considered necessary to indicate a mediating role for positive cognitions: (a) variation in the independent variable (caregiver depression) predicted variation in the outcome variable (children social behaviors/children problem behaviors), (b) variation in the independent variable (caregiver depression) predicted variation in the mediator variable (positive cognitions), and (c) prediction of children social behaviors/or problem behavior by caregiver depression was altered when positive cognition was entered into the model (Baron \& Kenny, 1986).

\section{Results}

The ages of caregivers ranged from 23 to 58 years $(M=41.05$; $\mathrm{SD}=6.0) ; 96.6 \%$ were females $(n=113)$ and $3.4 \%$ were males $(n=4)$. The great majority of the caregivers $(n=106)$ were Caucasian, representing $90.6 \%$ of the total sample; the remaining subjects were African American, Hispanic, or other. More than three quarters of the caregivers were married $(76.9 \% ; n=90), 15.4 \%$ were either divorced or separated $(n=18)$, and the remainder were either

Archives of Psychiatric Nursing, Vol. 30, No. 1 (February 2016): pg. 13-18. DOI. This article is @ Elsevier (WB Saunders) and permission has been granted for this version to appear in e-Publications@Marquette. Elsevier (WB Saunders) does not grant permission for this article to be further copied/distributed or hosted elsewhere without the express permission from Elsevier (WB Saunders). 
never married or widowed $(7.7 \% ; n=9)$. Two fifths $(40.2 \% ; n=47)$ of the caregivers had a college degree, $30.8 \%$ had some graduate/professional education ( $n=36$ ), $23.9 \%$ had some college or an associate degree $(n=28)$, and $5.1 \%$ had a high school diploma $(n=6)$. More than half of the sample $(61.5 \%)$ had incomes more than $\$ 45,000$ ( $n=72) ; 14.5 \%$ had incomes ranging from $\$ 5000$ to less than $\$ 20,000$ ( $n=17), 8.6 \%$ had incomes ranging from $\$ 20,000$ to less than $\$ 35,000(n=10)$, and $15.3 \%$ had incomes ranging from $\$ 35,000$ to less than $\$ 45,000(n=18)$. More than half $(58.1 \%)$ of the caregivers rated their health as good $(n=68), 19.7 \%$ rated their health as excellent $(n=23), 18.8 \%$ rated their health as fair $(n=22)$, and $3.4 \%$ rated their health as poor $(n=4)$. Almost all $(96.6 \%)$ of the caregivers were mothers of the person with ASD $(n=113)$ and $3.4 \%$ were fathers $(n=4)$. All of the caregivers lived with the person with autism full time $(n=117)$. Almost all $(92.3 \%)$ of the caregivers ( $n=108)$ provided care with daily activities; $6 \%(n=7)$ reported that they provided only some care, and only $1.7 \%(n=2)$ reported that they do not provide care.

Regarding the persons with autism, 85.5\% $(n=100)$ were males and $14.5 \%$ were females $(n=17)$. The ages of persons with ASD ranged from 3 to 17 years $(M=10.9 ; S D=3.3)$. Almost all $(84.6 \%)$ of persons with autism $(n=99)$ were Caucasian and the remaining were African American, Asian, or Hispanic $(n=18)$. Almost one third of the caregivers $(29.1 \%)$ reported that they have more than one child diagnosed with autism $(n=34)$. Years since diagnosis ranged from less than a year to 14 years $(M=7.5$; $S D=3.5)$.

Simple linear regression was used to examine the effects of positive cognitions on children social behavior domains. The overall model was statistically significant and explained $16 \%$ of the variance in children social behavior domains $(F(1,115)=23.62, P<0.001)$. Thus, positive cognitions had a direct positive effect on children social behavior domains ( $B=0.41, P<0.001)$ : as caregivers' positive cognitions increased, the children social behavior (compliant/adaptive) increased [Fig. 1, Q1 (a)]

Simple linear regression was used to examine the effects of positive cognitions on children problem behavior domains. The overall model was statistically significant and explained $8 \%$ of the variance in 
children problem behavior domains $(F(1,115)=11.59, P<0.001)$. Thus, positive cognitions had a direct negative effect on children problem behavior domains ( $B=-0.30, P<0.001)$ : as caregivers' positive cognitions increased, the children problem behavior decreased [Fig. 2, Q1 (b)]

\section{Mediation}

I. Mediation of positive cognition on the relationship between caregivers' depression and children's social behavior domains (Fig. 1, Q2, Table 1)

The first condition was supported by the findings showing that the overall regression equation was statistically significant, $F(1$, $115)=5.89, P<.05$, with $5 \%$ of the variance in children social behavior explained by caregiver depression. When children social behavior was regressed on caregiver depression, the results indicated that caregiver depression had a direct positive effect on children social behavior $(B=-.22, P<.05$; Fig. 1 , Q2, Path 1). The second condition was supported by the finding that the overall regression equation was statistically significant, $F(1,115)=78.90, P<.001$, with $40 \%$ of the variance in positive cognitions explained by caregiver depression (Fig. 1, Q2, Path 2). When positive cognitions were regressed on caregivers' depression, the results indicated that caregiver depression had a direct negative effect on positive cognitions ( $B=-.64, P<.001)$ : as depression increased, caregivers' positive cognitions decreased.

For the third condition, caregivers' depression was entered in the first step of the regression model and positive cognitions were entered in the second step. In Step 1, the model was significant, $F(1,115)=5.89, P<.05$, with $5 \%$ of the variance in children social behavior explained by caregiver depression. When positive cognitions were added in Step 2, there was a drop in the beta weight of caregiver depression, from $B=.22$ to .07 (Table 1, Test 1 ). The level of significance dropped from $P<.05$ to $P>05$, suggesting that the effect of caregiver 
NOT THE PUBLISHED VERSION; this is the author's final, peer-reviewed manuscript. The published version may be accessed by following the link in the citation at the bottom of the page.

depression on their children's social behavior was mediated by positive cognitions.

II. Mediation of positive cognition on the relationship between caregivers' depression and children's problem behavior domains (Fig. 2, Q3, Table 1).

The first condition was supported by the findings showing that the overall regression equation was statistically significant, $F(1,115)=16.00, P<.001$, with $12 \%$ of the variance in children problem behavior explained by caregiver depression. When children problem behavior was regressed on caregiver depression, the results indicated that caregiver depression had a direct positive effect on children problem behavior $(B=.35$, $P<.001$; Fig. 2, Q3, Path 1). The second condition was supported by the finding that the overall regression equation was statistically significant, $\mathrm{F}(1,115)=78.90, P<.001$, with $40 \%$ of the variance in positive cognitions explained by caregiver depression. When positive cognitions were regressed on caregivers' depression, the results indicated that caregiver depression had a direct negative effect on positive cognitions ( $\mathrm{B}=-.64, P<.001)$ : as depression increased, caregivers' positive cognitions decreased (Fig. 2, Q3, Path 2).

For the third condition, caregivers' depression was entered in the first step of the regression model and positive cognitions were entered in the second step. In Step 1, the model was significant, $F(1,115)=16.00, P<.001$, with $12 \%$ of the variance in children problem behavior explained by caregiver depression. When positive cognitions were added in Step 2, there was a drop in the beta weight of caregiver depression, from $B=.35$ to .26 (Table 1 , Test 2 ). The level of significance dropped from $P<.001$ to $P=.022$, suggesting that the effect of caregiver depression on their children's problem behavior was partially mediated by positive cognitions.

\section{Discussion}

The study was the first to investigate the mediating effects of positive cognitions on the relationship between caregivers' depression permission has been granted for this version to appear in e-Publications@Marquette. Elsevier (WB Saunders) does not grant permission for this article to be further copied/distributed or hosted elsewhere without the express permission from Elsevier (WB Saunders). 
and their children's challenging behaviors. Positive cognitions were found to have mediating effects on the relationship between caregiver's depression and their children's challenging behaviors in this sample of caregivers of persons with ASD. These findings are consistent, in part, with the findings of Bekhet (2013), in which Positive cognitions were found to have a mediating effects on the relationship between caregiver's burden and resourcefulness in dementia caregivers (Bekhet, 2013). The results also are consistent with previous research by Zauszniewski, Bekhet, and Suresky (2009) who found that positive cognitions acted as a mediator of caregiver burden in a sample of 60 female family caregivers of persons with serious mental illness (Zauszniewski et al., 2009). In addition, positive cognitions were found to have a direct positive effect on resourcefulness in a sample of 104 relocated elders (Bekhet et al., 2008). In the light of Goodman and Gotlib's integrative model as well as Karazsia and Wildman's model of parenting strategies, maternal depression affects children's challenging behaviors and this relationship is mediated/attenuated by positive cognitions. Therefore, caregivers of persons with ASD could benefit from positive thinking interventions. Positive thinking interventions will help caregivers to reframe the situations positively, use positive self-talk, and interrupt their pessimistic thoughts by music and or relaxation techniques. Positive thinking interventions will help them to focus on the here and now while planning for their future.

The skills within the positive thinking training (PTT) intervention developed by the researcher is based on cognitive behavior theory and reflect cognitive activities to increase positive thoughts and to eliminate or modify negative ones (Bekhet \& Zauszniewski, 2013). The PTT intervention is innovative in using principles of learning and memory enhancement. More specifically, the PTT intervention uses mnemonic strategies that include an acronym, chunking, and homework reinforcement for teaching and recalling the PTT skills (Thornton \& Conway, 2013). An acronym, by definition, is formed by the first letter of words or groups of words to form a new word. The acronym "THINKING" is used to facilitate learning and recall of the eight positive thinking strategies as follows: Transforming negative thoughts into positive thoughts, Highlighting positive aspects of the situation, Interrupting pessimistic thoughts by using relaxation techniques and distraction, Noting the need to practice positive permission has been granted for this version to appear in e-Publications@Marquette. Elsevier (WB Saunders) does not grant permission for this article to be further copied/distributed or hosted elsewhere without the express permission from Elsevier (WB Saunders). 
thinking, Knowing how to break a problem into smaller parts to be manageable, Initiating optimistic beliefs with each part of the problem, Nurturing ways to challenge pessimistic thoughts, Generating positive feelings by controlling negative thoughts ( Bekhet \& Zauszniewski, 2013). "Chunking" is another mnemonic strategy and it refers to the common rule that a person can remember between five and nine things at one time. The word THINKING contains eight letters, which is a reasonable "chunk" of ideas for the caregivers to remember. Reinforcement is another mnemonic strategy. In fact, the skills constituting positive thinking must be reinforced and practiced, not just learned. Therefore, caregivers will be given a weekly homework to see whether they have applied the PTT skills that they have learned in the PTT intervention

Limitations of the study include the use of convenience sample of caregivers of persons with ASD who uses the internet. Therefore, the results cannot be generalized to all caregivers of persons with ASD and it might be generalized only to those who use the internet. However, recruiting through the internet has the advantage of recruiting a national sample of ASD caregivers, which enrich the study. Another limitation is that the study was cross-sectional, therefore, caregivers' depression and positive cognitions as well as their children's challenging behaviors could not be assessed overtime. Future longitudinal studies might be beneficial in measuring the effects of positive cognitions interventions on caregivers' burden and on their children's challenging behaviors immediately, six weeks, and three months post intervention.

Many recent statistical mediation analysis have been suggested in the new millennium (Preacher and Hayes, 2008 and Shrout and Bolger, 2002). This bootstrapping method provides some advantages mainly an increase in power. For example, the Preacher and Hayes Bootstrapping method is a non-parametric test that does not violate assumptions of normality and is therefore recommended for small sample sizes (Preacher \& Hayes, 2004). The current study uses an old approach, which is Baron and Kenny for testing the statistical significance of indirect effects (i.e., mediator variables) in multiple regression contexts, commonly known as "the normal theory approach" (Baron and Kenny, 1986 and Mallinckrodt et al., 2006). In fact, this method relies on the assumption that indirect (i.e., permission has been granted for this version to appear in e-Publications@Marquette. Elsevier (WB Saunders) does not grant permission for this article to be further copied/distributed or hosted elsewhere without the express permission from Elsevier (WB Saunders). 
mediation) effects are normally distributed. Given the fact that the variables in this study are normally distributed, this method has been used appropriately. In addition, the general rule of thumb as suggested by MacKinnon, Lockwood, Lockwood, West, and Sheets (2002) is that a sample size of 1000 is required to detect a small effect, a sample size of 100 is sufficient in detecting a medium effect, and a sample size of 50 is required to detect a large effect. In fact, based on previous research by the researchers with caregivers of persons with ASD (Bekhet, Johnson, \& Zauszniewski, 2012), a medium effect size is used in the current study, therefore a sample of 117 caregivers in the current study is justifiable.

A limitation that has become a general concern in pediatric research is the accuracy of maternal rating of child's behavior. This may be of concern as mothers' burden and levels of depression might affect their ratings of their child's behavior. In fact, there are three functional behavioral assessment methods that have been identified in the literature, namely, direct observation, informant methods, and functional analysis (Cooper et al., 2007, Miltenberger, 2008 and O'Neill et al., 1997). The method used in this study is the informant method, also known as indirect method and involves interviews and or questionnaires that can be completed by the parents, staff members, and or teachers (Miltenberger, 2008). Future research might consider using direct observation methods in which an observer would watch the child engage in activities within their natural environment (Miltenberger, 2008). Future research might also consider the use of functional analysis in which practitioners/researchers deliberately changing what happens before and/or after the behavior (antecedents and consequences) in an effort to test what might be causing the behavior (Cooper et al., 2007, Miltenberger, 2008 and O'Neill et al., 1997).

Despite these limitations, the findings add to our understanding of the relationships among caregivers' depression, positive cognitions, and their children's challenging behaviors.

In fact, nurses are in a strategic position to include in their interventions those strategies that strengthen positive cognitions in order to improve the caregivers' positive cognitions, which, in turn will have an impact on their children's challenging behaviors. permission has been granted for this version to appear in e-Publications@Marquette. Elsevier (WB Saunders) does not grant permission for this article to be further copied/distributed or hosted elsewhere without the express permission from Elsevier (WB Saunders). 
NOT THE PUBLISHED VERSION; this is the author's final, peer-reviewed manuscript. The published version may be accessed by following the link in the citation at the bottom of the page.

\section{Acknowledgment}

This research was funded by the 2014 International Society of Psychiatric Mental Health Nurses (ISPN) Foundation Research Grant awarded to Dr. Abir Bekhet (grant 74737).

\section{References}

Allik et al., 2006. L. Allik, J. Larsson, H. Smedje. Health-related quality of life in parents of school-age children with Asperger syndrome or highfunctioning autism. Health and Quality of Life Outcomes, 4 (2006), pp. $1-4$

Almansour et al., 2013. M.A. Almansour, M.A. Alateeq, M.K. Alzahrani, M.A. Algeffari, H.T. Alhomaidan. Depression and anxiety among parents and caregivers of autistic spectral disorder children. Neurosciences, 18 (1) (2013), pp. 58-63

Aman et al., 1996. M.G. Aman, M.J. Tasse, J. Rojahn, D. Hammer. The Nisonger Child Behavior Rating Form: A child behavior rating form for children with developmental disabilities. Research in Developmental Disabilities, 17 (1) (1996), pp. 41-57

American Psychiatric Association, 2000. American Psychiatric Association. Diagnostic and statistical manual of mental disorders. (4th ed.)Author, Washington, DC (2000)

Baker and Jeste, 2015. E. Baker, S. Jeste. Diagnosis and management of autism spectrum disorder in the Era of genomics: Rare disorders can pave the way for targeted treatments. Pediatric Clinics of North America, 62 (3) (2015), pp. 607-618

Baker et al., 2011. J.K. Baker, M.M. Seltzer, J.S. Greenberg. Longitudinal effects of adaptability on behavior problems and maternal depression in families of adolescents with autism. Journal of Family Psychology, 25 (4) (2011), pp. 601-609

Baron and Kenny, 1986. R.M. Baron, D.A. Kenny. The moderator-mediator variable distinction in social psychological research. Journal of Personality and Social Psychology, 51 (1986), pp. 1173-1182

Bekhet, 2013. A. Bekhet. Effects of positive cognitions and resourcefulness on caregiver burden among caregivers of persons with dementia. International Journal of Mental Health Nursing, 22 (2013), pp. 340346

Bekhet, 2014. A. Bekhet. Self-assessed health in caregivers of persons with autism: Associations with depressive symptoms, positive cognitions, resourcefulness, and well-being. Perspectives in Psychiatric Care, 50 (2014), pp. 210-217

Archives of Psychiatric Nursing, Vol. 30, No. 1 (February 2016): pg. 13-18. DOI. This article is @ Elsevier (WB Saunders) and permission has been granted for this version to appear in e-Publications@Marquette. Elsevier (WB Saunders) does not grant permission for this article to be further copied/distributed or hosted elsewhere without the express permission from Elsevier (WB Saunders). 
NOT THE PUBLISHED VERSION; this is the author's final, peer-reviewed manuscript. The published version may be accessed by following the link in the citation at the bottom of the page.

Bekhet et al., 2012. A. Bekhet, N. Johnson, J.A. Zauszniewski. Effects on resilience of caregivers of persons with autism spectrum disorder: The role of positive cognitions. Journal of the American Psychiatric Nurses Association, 18 (6) (2012), pp. 337-344

Bekhet and Zauszniewski, 2008. A. Bekhet, J.A. Zauszniewski. Theoretical substruction illustrated by the theory of learned resourcefulness. Research and Theory for Nursing Practice, 22 (3) (2008), pp. 205-214

Bekhet and Zauszniewski, 2013. A. Bekhet, J. Zauszniewski. Measuring Use of positive thinking skills scale: Psychometric testing of a new scale. Western Journal of Nursing Research, 35 (8) (2013), pp. 1074-1093

Bekhet et al., 2008. A. Bekhet, J.A. Zauszniewski, M. Wykle. Milieu change and relocation adjustment in elders. Western Journal of Nursing Research, 30 (1) (2008), pp. 113-129

Benson, 2006. P. Benson. The impact of symptoms severity of depressed mood among parents of children with ASD. Journal of Autism and Developmental Disorders, 36 (5) (2006), pp. 685-695

Cooper et al., 2007. J. Cooper, T. Heron, W. Heward. Applied behaviour analysis. Pearson Education, New Jersey (2007)

Ekas et al., 2010. N.V. Ekas, D.M. Lickenbrock, T.L. Whitman. Optimism, social support, and well- being in mothers of children with autism spectrum disorder. Journal of Autism and Developmental Disorders, 40 (10) (2010), pp. 1274-1284

Ekas et al., 2009. N.V. Ekas, T.L. Whitman, C. Shivers. Religiosity, spirituality, and socioemotional functioning in mothers of children with autism spectrum disorder. Journal of Autism and Developmental Disorders, 39 (5) (2009), pp. 706-719

Firth and Dryer, 2013. I. Firth, R. Dryer. The predictors of distress in parents of children with autism spectrum disorder. Journal of Intellectual \& Developmental Disability, 38 (2) (2013), pp. 163-171

Goodman and Gotlib, 1999. S.H. Goodman, I.H. Gotlib. Risk for psychopathology in the children of depressed mothers: a developmental model for understanding mechanisms of transmission. Psychological Review, 106 (3) (1999), pp. 458-490

Herring et al., 2006. S. Herring, K. Gray, J. Taffe, B. Tonge, D. Sweeney, S. Einfeld. Behavior and emotional problems in toddlers with pervasive developmental disorders and developmental delay: associations with parental mental health and family functioning. Journal of Intellectual Disability Research, 50 (12) (2006), pp. 874-882

Hoffman et al., 2008. C. Hoffman, D. Sweeney, M. Lopez-Wagner, D. Hodge, C. Nam, B. Botts. Children with autism: Sleep problems and mother's stress. Focus on Autism and Other Developmental Disabilities, 23 (3) (2008), pp. 155-165

Archives of Psychiatric Nursing, Vol. 30, No. 1 (February 2016): pg. 13-18. DOI. This article is (C Elsevier (WB Saunders) and permission has been granted for this version to appear in e-Publications@Marquette. Elsevier (WB Saunders) does not grant permission for this article to be further copied/distributed or hosted elsewhere without the express permission from Elsevier (WB Saunders). 
NOT THE PUBLISHED VERSION; this is the author's final, peer-reviewed manuscript. The published version may be accessed by following the link in the citation at the bottom of the page.

Karazsia and Wildman, 2009. B.T. Karazsia, B.G. Wildman. The mediating effects of parenting behaviors on maternal affect and reports of children's behaviors. Journal of Child and Family Studies, 18 (2009), pp. 342-349

Karst and Van Hecke, 2012. J.S. Karst, A.V. Van Hecke. Parent and Family impact of autism spectrum disorders: A review and proposed model for intervention evaluation. Clinical Child and Family Psychology Review, 15 (3) (2012), pp. 247-277

Khanna et al., 2011. R. Khanna, S.S. Madhavan, M.J. Smith, J.H. Patrick, C. Tworek, B. Becker-Cottrill. Assessment of health-related quality of life among primary caregivers of children with autism spectrum disorders. Journal of Autism and Developmental Disorders, 41 (2011), pp. 12141227

Kirby et al., 2015. A.V. Kirby, T.J. White, G.T. Baranek. Caregiver strain and sensory features in children with autism spectrum disorder and other developmental disabilities. American Journal on Intellectual and Developmental Disabilities, 120 (1) (2015), pp. 32-45

Lecavalier et al., 2006. L. Lecavalier, S. Leone, J. Wiltz. The impact of behavior problems on caregiver stress in young people with autism spectrum disorders. Journal of Intellectual Disability Research, 50 (3) (2006), pp. 172-183

Lewinsohn et al., 1997. P.M. Lewinsohn, J.R. Seeley, R.E. Roberts, N.B. Allen. Center for Epidemiological Studies-Depression Scale (CES-D) as a screening instrument for depression among community-residing older adults. Psychology and Aging, 12 (1997), pp. 277-287

Mackinnon et al., 2002. D.P. MacKinnon, C.M. Lockwood, J.M. Lockwood, S.G. West, V. Sheets. A comparison of methods to test mediation and other intervening variable effects. Psychological Methods, 7 (1) (2002), pp. 83-104

Mallinckrodt et al., 2006. B. Mallinckrodt, T. Abraham, M. Wei, D. Russell. Advances in testing the statistical significance of mediation effects. Journal of Counseling Psychology, 53 (3) (2006), pp. 372-378

Miltenberger, 2008. R. Miltenberger. Behaviour modification. Wadsworth Publishing, Belmont, CA (2008)

National Autism Association, 2014. National Autism Association. Autism fact sheet. Retrieved

from: http://nationalautismassociation.org/resources/autism-factsheet/ (2014)

O'Neill et al., 1997. R. O'Neill, R. Horner, R. Albin, J. Sprague, K. Storey, J. Newton. Functional assessment and programme development for problem behaviour: A practical handbook. Brooks/Cole Publishing Company, Pacific Grove, CA (1997)

Archives of Psychiatric Nursing, Vol. 30, No. 1 (February 2016): pg. 13-18. DOI. This article is (C Elsevier (WB Saunders) and permission has been granted for this version to appear in e-Publications@Marquette. Elsevier (WB Saunders) does not grant permission for this article to be further copied/distributed or hosted elsewhere without the express permission from Elsevier (WB Saunders). 
Phetrasuwan and Miles, 2009. S. Phetrasuwan, M. Miles. Parenting stress in mothers of children with autism spectrum disorders. Journal of Pediatric Nursing, 14 (3) (2009), pp. 157-165

Preacher and Hayes, 2004. K.J. Preacher, A.F. Hayes. SPSS and SAS procedures for estimating indirect effects in simple mediation models. Behavior Research Methods, Instruments, and Computers, 36 (4) (2004), pp. 717-731

Preacher and Hayes, 2008. K.J. Preacher, A.F. Hayes. Asymptotic and resampling strategies for assessing and comparing indirect effects in multiple mediator models. Behavior Research Methods, 40 (3) (2008), pp. 879-891

Radloff, 1977. L.S. Radloff. The CES-D Scale: A self-report depression scale for research in the general population. Applied Psychological Measurement, 1 (1977), pp. 385-401

Raposa et al., 2014. E. Raposa, C. Hammen, P. Brennan, J. Najman. The long-term effects of maternal depression: early childhood physical health as a pathway to offspring depression. The Journal of Adolescents Health, 54 (1) (2014), pp. 88-93

Shrout and Bolger, 2002. P.E. Shrout, N. Bolger. Mediation in experimental and nonexperimental studies: New procedures and recommendations. Psychological Methods, 7 (2002), pp. 422-445

Smith et al., 2008. L. Smith, M. Seltzer, H. Tager-Flusberg, J. Greenberg, A. Carter. A Comparative analysis of well-being and coping among mothers of toddlers and mothers of adolescents with ASD. Journal of Autism and Developmental Disorders, 38 (5) (2008), pp. 876-889

Strang et al., 2012. J.F. Strang, L. Kenworthy, P. Daniolos, L. Case, M.C. Wills, A. Martin, G.L. Wallace. Depression and anxiety symptoms in children and adolescents with autism spectrum disorders without intellectual disability. Research in Autism Spectrum Disorder, 6 (1) (2012), pp. 406-412

Tassé et al., 1996. M.J. Tassé, M.G. Aman, D. Hammer, J. Rojahn. The Nisonger Child Behavior Rating Form: Age and gender effects and norms. Research in Developmental Disabilities, 17 (1996), pp. 59-75

Thornton and Conway, 2013. M.A. Thornton, A.R. Conway. Working memory for social information: Chunking or domain-specific buffer? NeuroImage, 70 (15) (2013), pp. 233-239

Zauszniewski, 1995. J.A. Zauszniewski. Development and testing of a measure of depressive cognition in older adults. Journal of Nursing Measurement, 3 (1) (1995), pp. 31-41

Zauszniewski, 1997. J.A. Zauszniewski. The Depressive Cognition Scale:

Further psychometric evaluation. Journal of Nursing Measurement, 5 (2) (1997), pp. 191-200

Archives of Psychiatric Nursing, Vol. 30, No. 1 (February 2016): pg. 13-18. DOI. This article is @ Elsevier (WB Saunders) and permission has been granted for this version to appear in e-Publications@Marquette. Elsevier (WB Saunders) does not grant permission for this article to be further copied/distributed or hosted elsewhere without the express permission from Elsevier (WB Saunders). 
NOT THE PUBLISHED VERSION; this is the author's final, peer-reviewed manuscript. The published version may be accessed by following the link in the citation at the bottom of the page.

Zauszniewski et al., 2009. J.A. Zauszniewski, A. Bekhet, M.J. Suresky. Effects on resilience of women family caregivers of seriously mentally ill adults: The role of positive cognitions. Archives of Psychiatric Nursing, 23 (6) (2009), pp. 412-422

Zauszniewski et al., 2001. J.A. Zauszniewski, C.W. Chung, K. Krafcik, V.D. Sousa. Psychometric testing of the Depressive Cognition Scale in women with type 2 diabetes. Journal of Nursing Measurement, 9 (1) (2001), pp. 61-72

Zauszniewski et al., 2002. J.A. Zauszniewski, P.E. McDonald, K. Krafcik, C.W. Chung. Acceptance, cognitions, and resourcefulness in women with diabetes. Western Journal of Nursing Research, 24 (7) (2002), pp. 728-741

Corresponding Author: Abir K. Bekhet, PhD, RN, H.S.M.I., Associate Professor of Mental Health Nursing, Marquette University College of Nursing, Clark Hall 530 N. 16th Street, Milwaukee, WI 53233. permission has been granted for this version to appear in e-Publications@Marquette. Elsevier (WB Saunders) does not grant permission for this article to be further copied/distributed or hosted elsewhere without the express permission from Elsevier (WB Saunders). 